\title{
Evaluation of Hypothermia in Sick Neonates as Predictor of Fatality at a Tertiary Care Center of Eastern Nepal
}

\author{
Kanodia Piush ${ }^{1}$, Bhandari $\mathrm{R}^{2}$, Bhatta $\mathrm{N}^{3}$, Yadav $\mathrm{S}^{4}$
}

\begin{abstract}
Introduction: Hypothermia is a common and frequent problem in newborns. It has larger impact in outcome related to management of sick infants. Objective: To correlate the severity of hypothermia in sick extramural neonates with fatality and physiological derangements. Materials and Methods: This prospective observational study was carried out at Neonatology unit of Pediatric department of B. P. Koirala Institute of Health Sciences (BPKIHS) Dharan. Total 200 extramural hypothermic neonates were transferred to BPKIHS from June 2015 to June 2016. Neonates weighing more than $1000 \mathrm{~g}$, with abdominal skin temperature less than $36.5^{\circ} \mathrm{C}$ at admission were included in the study.. Clinical features and associated features were recorded at the time of admission. Oxygen saturation was recorded by a pulse oximeter. Results: Fatality was observed to be $39.3 \%$ in mildly hypothermic babies, $51.6 \%$ in moderately hypothermic babies and $80 \%$ in severely hypothermic babies. However, the presence of associated illness (birth asphyxia, neonatal sepsis and respiratory distress), physiological derangements (hypoxia, hypoglycemia and shock) and weight less than $2000 \mathrm{~g}$ were associated with more than $50 \%$ fatality even in mildly hypothermic babies. When moderate hypothermia was associated with hypoxia or shock, the fatality was $83.3 \%$ and $90.9 \%$, respectively. Similarly, mild hypothermia with hypoglycemia was associated with $71.4 \%$ fatality. Conclusion: The presence of associated illness (birth asphyxia, neonatal sepsis and respiratory distress), physiological derangements (hypoxia, hypoglycemia and shock) and weight less than $2000 \mathrm{~g}$ should be considered adverse factors in hypothermic neonates. Their presence should classify hypothermia in the next higher category of severity in WHO classification.
\end{abstract}

Key words: Hypothermia, hypoxia, newborn

\section{INTRODUCTION}

Hypothermia (defined by World Health Orgnization as temperature less than $36.5^{\circ} \mathrm{C}$ ) is an important and major cause of death in newborn ${ }^{1-6}$. Hypothermia is more common than hyperthermia in newborn. Septicemia and hypoxemia are usually complicated by hypothermia, hypoglycemia and hypoperfusion ${ }^{7}$. WHO classification for hypothermia has not been evaluated with reference to fatality and associated sickness. This prompted us to undertake the present study with an objective of correlating the severity of hypothermia (WHO classification) in sick extramural neonates with fatality.

\section{MATERIALS AND METHODS}

A total of 200 extramural hypothermic neonates transported to a referral neonatal unit of BPKIHS were enrolled for the study. Neonates with abdominal skin temperature less than $36.5^{\circ} \mathrm{C}$ at admission were included in the study. Neonates weighing less than 1000 g. were excluded. Clinical features including age,

1. Dr. Piush Kanodia

2. Dr. Rupa Bhandari

3. Dr. Nisha Bhatta

4. Dr. Sunil Yadav

\section{Address for correspondence:}

Dr. Piush Kanodia

Department of Pediatrics

National Medical College \& Teaching Hospital

Nealgunj, Banke, Nepal

Email: piushkanodia@yahoo.com weight, gestational age, clinical diagnosis, vitals and place of delivery were recorded at the time of admission. The diagnosis of associated morbidity was made as per the guidelines by National Neonatology Forum (NNF) of India ${ }^{8}$. Oxygen saturation was recorded with the help of a pulse oximeter. Perfusion was assessed by seeing the capillary filling time. Blood glucose levels were measured at the initiation of rewarming by using dextrostix ${ }^{9}$.

\section{RESULTS}

The mean abdominal skin temperature was $34.93 \pm 1.3^{\circ} \mathrm{C}$. Seventy two percent of the babies were moderately or severely hypothermic as per WHO classification. Fatality was 39.3\%, $51.6 \%$ and $80 \%$ in mildly, moderately and severely hypothermic babies, respectively.

Considering place of delivery, $52 \%$ of the total was home deliveries and $48 \%$ were hospital deliveries (Table I). Difference in fatality between hypothermic babies weighing less than $2000 \mathrm{~g}$ and those weighing more than $2000 \mathrm{~g}$ was significant ( $p=0.0276$ ). With regard to morbidity, $56 \%$ of babies were asphyxiated, $73 \%$ had sepsis, $19 \%$ had pneumonia, $42 \%$ had respiratory distress (meconium aspiration syndrome in 17\%, hyaline membrane disease in $6 \%$ and pneumonia in 19\%) (Table II). Lethargy, refusal to feed, and respiratory distress were the most common symptoms. Sclerema was found in $21 \%$ of hypothermic babies. Of these, $76.2 \%$ were either moderately hypothermic or severely hypothermic (Table III). 


\begin{tabular}{|l|c|c|c|c|}
\hline & $\begin{array}{c}\text { All hypothermic } \\
(\mathbf{n = 2 0 0 )}\end{array}$ & $\begin{array}{c}\text { Mild hypothermia } \\
(\mathbf{n = 5 6 )}\end{array}$ & $\begin{array}{c}\text { Moderate hypothermia } \\
(\mathbf{n = 1 2 4 )}\end{array}$ & $\begin{array}{c}\text { Severe hypothermia } \\
(\mathbf{n = 2 0})\end{array}$ \\
\hline $\begin{array}{l}\text { Abdominal skin temp. }\left({ }^{\circ} \mathrm{C}\right) \\
\text { Mean } \pm \text { SD }\end{array}$ & $34.93 \pm 1.397$ & $36.136 \pm 0.073$ & $34.93 \pm 0.746$ & $31.5 \pm 0.291$ \\
\hline Weight (g) Mean \pm SD & $1969.5 \pm 719.9$ & $2049 \pm 721$ & $1936 \pm 715.4$ & $1954 \pm 804$ \\
\hline Gestational age & & & & 8 \\
\hline Pre-term(<37weeks) & 70 & 14 & 78 & 12 \\
\hline Term (37-42 weeks) & 124 & 36 & 0 & 0 \\
\hline Post-term (>42 weeks) & 6 & 6 & $41.85 \pm 38.54$ & $5.6 \pm 3.12$ \\
\hline Age (hours) Mean \pm SD & $56.45 \pm 48.32$ & $92.57 \pm 86.11$ & & 16 \\
\hline Gender of baby & & & 52 & 4 \\
\hline Male & 104 & 36 & 72 & 8 \\
\hline Female & 96 & 20 & 66 & 12 \\
\hline Place of delivery & & & 58 & \\
\hline Home & 104 & 30 & & 2 \\
\hline Hospital & 96 & 26 & 48 & 16 \\
\hline Intrauterine growth & & 22 & 76 & 2 \\
\hline SGA & 72 & 34 & 0 & \\
\hline AGA & 126 & 0 & & \\
\hline LGA & 2 & & & \\
\hline
\end{tabular}

Table I: Clinical profile of study subjects

\begin{tabular}{|l|c|c|c|c|}
\hline & $\begin{array}{c}\text { No. of all } \\
\text { hypothermics } \\
\text { (Fatality \%) }\end{array}$ & $\begin{array}{c}\text { Newborn with Mild } \\
\text { hypothermia } \\
\text { (Fatality \%) }\end{array}$ & $\begin{array}{c}\text { Newborn with } \\
\text { Moderate hypothermia } \\
\text { (Fatality \%) }\end{array}$ & $\begin{array}{c}\text { Newborn with } \\
\text { Severe hypothermia } \\
\text { (Fatality \%) }\end{array}$ \\
\hline Birth asphyxia & $100(56)$ & $24(50)$ & $60(50)$ & $16(87.5)$ \\
\hline Sepsis & $146(63)$ & $40(55)$ & $94(63.8)$ & $12(100)$ \\
\hline Respiratory distress & $84(71.4)$ & $34(41.6)$ & $38(79.2)$ & $12(100)$ \\
\hline
\end{tabular}

Table II: Associated morbidity at admission in study subjects

\begin{tabular}{|l|c|c|c|c|}
\hline & $\begin{array}{c}\text { No. of all } \\
\text { hypothermics } \\
\text { (Fatality \%) }\end{array}$ & $\begin{array}{c}\text { Newborn with Mild } \\
\text { hypothermia } \\
\text { (Fatality \%) }\end{array}$ & $\begin{array}{c}\text { Newborn with } \\
\text { Moderate hypothermia } \\
\text { (Fatality \%) }\end{array}$ & $\begin{array}{c}\text { Newborn with } \\
\text { Severe hypothermia } \\
\text { (Fatality \%) }\end{array}$ \\
\hline Lethargy & $186(53.8)$ & $48(45.8)$ & $120(51.7)$ & $18(88.9)$ \\
\hline Seizures & $28(57.1)$ & $8(25)$ & $16(62.5)$ & $4(100)$ \\
\hline Jaundice & $12(66.7)$ & $2(100)$ & $8(50)$ & $2(100)$ \\
\hline Vomiting & $8(50)$ & $2(100)$ & $6(33.3)$ & $0(0)$ \\
\hline Respiratory distress & $68(44.1)$ & $22(9.1)$ & $40(60)$ & $6(66.7)$ \\
\hline Sclerema & $42(80.9)$ & $10(60)$ & $20(80)$ & $12(100)$ \\
\hline Peripheral cyanosis & $58(48.3)$ & $12(16.6)$ & $34(47.1)$ & $12(83.3)$ \\
\hline
\end{tabular}

Table III: Correlation of clinical features with severity of hypothermia 


\begin{tabular}{|l|c|c|c|c|}
\hline & $\begin{array}{c}\text { No. of all } \\
\text { hypothermics } \\
\text { (Fatality \%) }\end{array}$ & $\begin{array}{c}\text { Newborn with Mild } \\
\text { hypothermia } \\
\text { (Fatality \%) }\end{array}$ & $\begin{array}{c}\text { Newborn with } \\
\text { Moderate hypothermia } \\
\text { (Fatality \%) }\end{array}$ & $\begin{array}{c}\text { Newborn with } \\
\text { Severe hypothermia } \\
\text { (Fatality \%) }\end{array}$ \\
\hline Hypoxia* & $94(70.2 \%)$ & $32(43.8 \%)$ & $48(83.3 \%)$ & $14(85.7 \%)$ \\
\hline Shock** & $30(86.7 \%)$ & $4(50 \%)$ & $22(90.9 \%)$ & $4(100 \%)$ \\
\hline Hypoglycemia $^{*}$ & $70(65.7 \%)$ & $14(71.4 \%)$ & $54(62.9 \%)$ & $2(100 \%)$ \\
\hline
\end{tabular}

${ }^{*} \mathrm{SPO}_{2}<90 \%$, ** CFT $>3 \mathrm{~s}$, \# Blood Sugar $<45 \mathrm{gm} / \mathrm{dl}$

Table IV: Variables in study subjects

\begin{tabular}{|l|c|c|c|}
\hline & No. & No. expired & Fatality \% \\
\hline Hypothermia alone & 70 & 1825.6 & 42.9 \\
\hline Hypothermia + hypoglycaemia & 28 & 12 & 52.1 \\
\hline Hypothermia + hypoxia & 48 & 24 & 78.57 \\
\hline Hypothermia + hypoglycemia + hypoxia & 28 & 22 & 75 \\
\hline Hypothermia + hypoglycemia + shock & 8 & 6 & 87.5 \\
\hline Hypothermia + hypoxia + shock & 16 & 14 & 100 \\
\hline Hypothermia + hypoglycemia + Hypoxia + shock & 6 & 6 & 51 \\
\hline Total & 200 & 102 & \\
\hline
\end{tabular}

Table V: Correlation of combinations of physiological derangements with fatality in all hypothermic babies

Hypoxia, shock and hypoglycemia were detected at admission in $47 \%, 15 \%$ and $35 \%$, respectively. The fatality was significantly increased when hypothermia was associated with hypoxia, shock or hypoglycemia $(p=0.033, p=0.012$, and $p=0.0249$, respectively) (Table IV). When moderate hypothermia was associated with hypoxia or shock, the fatality was $83.3 \%$ and $90.9 \%$, respectively. Similarly, mild hypothermia with hypoglycemia was associated with $71.4 \%$ fatality.

Fatality was found to increase with increasing physiological derangements (Table V). Hypothermia associated with other physiological derangements (hypoxia, shock, hypoglycemia) was found to have a higher fatality as compared to hypothermia alone $(p=0.0494)$.

\section{DISCUSSION}

About 17 million neonates develop hypothermia in the developing world ${ }^{1}$. Hypothermic newborns are more likely to die than those admitted with normal temperatures ${ }^{13,14}$. In the present study, fatality was $39.3 \%$ in mildly hypothermic babies, $51.6 \%$ in moderately hypothermic babies and $80 \%$ in severely hypothermic babies. As per the knowledge this is the first study of nation correlating fatality with severity of hypothermia.

According to WHO classification of hypothermia ${ }^{13}$ the newborn with a body temperature of $36-36.4^{\circ} \mathrm{C}$ is under cold stress (mild hypothermia). A baby with a temperature of $32-35.9^{\circ} \mathrm{C}$ and temperature below $32^{\circ} \mathrm{C}$ is considered as moderate hypothermia and severe hypothermia respectively. Mild hypothermi is a sign for concern. while a Moderate hypothermia and Severe hypothermia has been associated with grave outlook requiring urgent skilled care.

Although the WHO classification is based solely on temperature of the newborn, sickness is a frequent association with neonatal hypothermia. Physiological derangements like hypoxia, hypoglycemia and shock set up a perpetuating cycle with hypothermia. Hence, neonatal morbidities like birth asphyxia, sepsis and respiratory distress are important factors affecting the outcome in hypothermic neonates. However, the WHO classification of hypothermia does not take into account these easily assessable morbidities. The present study found a strong association of these clinical parameters in predicting fatality.

Severely hypothermic neonates are critically sick and known to require intensive care.$^{13}$ However, in our study, even in mild and moderate hypothermia, the fatality was increased significantly in the presence of associated illness (birth asphyxia, neonatal sepsis and respiratory distress) and physiological derangements (hypoxia, hypoglycemia and shock). Similarly, mildly hypothermic neonates weighing less than $2000 \mathrm{~g}$ had $59.3 \%$ fatality. Hence, their mere presence should classify a hypothermic neonate to a higher category of severity.

The site of measurement of hypothermia is not specified in WHO classification. In the present study, body temperature was measured by abdominal skin temperature recorded with the help of a thermistor probe attached to the upper abdomen. 
This method has been shown to be representative of the core temperature, is reliable for the diagnosis of hypothermia ${ }^{1}$ and has been used in some of the earlier studies ${ }^{1,3,4,15-16}$. As the abdominal skin does not vasconstrict, it can be used as an indicator of central temperature and is easier and safer than using the rectum.

\section{CONCLUSION}

WHO classification of severity of hypothermia correlates with risk of fatality. However, it considers only body temperature to classify severity of hypothermia. The presence of weight less than $2000 \mathrm{~g}$, associated illness (birth asphyxia, neonatal sepsis and respiratory distress) and physiological derangements (hypoxia, hypoperfusion and hypoglycemia) should be considered adverse factors in hypothermic neonates. Their presence should classify hypothermia in the next higher category of severity in WHO classification.

\section{REFERENCES}

1. Singh M, Rao G, Malhotra AK, Deorari AK. Assessment of newborn baby's temperature by human touch: a potentially useful primary care strategy. Indian Pediatr 1992; 29: 449-52.

2. Karan S, Rao MN, Urmila S, Rajaji S. The incidence, clinical profile, morbidity and mortality of hypothermia in the newborn. Indian Pediatr 1975; 12: 1205-10.

3. Day RL, Caliquiri L, Kamenski C, Ehlrich F. Body temperature and survival of premature infant. Pediatrics1964; 34: 171-81.

4. Silverman WA, Fertig JW, Berger AP. The influence of thermal environment upon survival of premature infants. Pediatrics1958; 22: 876-86.

5. Daga S. Determinants of death among admissions to intensive care units for newborns. J Trop Pediatr 1991; 37: 53-55.

6. Arneil GC, Kerr MM. Severe hypothermia in Glasgow infants in winter. Lancet1963; 2: 756-59.

7. Yu JS, Jackson R.Neonatal hypothermia in Australia. Practitioner 1974; 213: 790-94.

8. National Neonatology Forum. National neonatal perinatal database. Report for the year 1995 Secretariat National Neonatology Forum, New Delhi.

9. Huggett A, Nixon DA. The use of glucose oxidase, peroxidase and O-didanosine in determination of blood and urinary glucose. Lancet 1957; 273: 368-74.

10. Thermal Protection of the Newborn: A Practical Guide. WHO/RHT/MSM/97.2.1997, pp. 17-22.

11. Ji XC, Zhu CY, Pang RY. Epidemiological study on hypothermia in newborn. Chinese Med J 1993; 106: 428-32.
12. Lyon AJ, Pikaar ME, Badger P, Mclntosh N. Temperature control in very low birthweight infants during first five days of life. Arch Dis Child Fetal Neonatal Ed 1997; 76: F47-F50.

13. Kaplan M, Eidelman AJ. Improved prognosis in severely hypothermic newborn infants treated by rapid rewarming. J Pediatr1984; 105: 470-74.

14. Tafari N, Gentz J. Aspects on rewarming newborn infants with severe accidental hypothermia. Acta Pediatr Scand 1974; 63: 595-600.

15. Gandy GM, Adamsons K, Cunningham N, Silverman WA, James LS. Thermal environment and acid base homeostasis in human infants during first few hours of life. J Clin Invest1964; 43: 751-58.

16. Stephenson JM, Du JN, Oliver TK. The effect of cooling on blood gas tensions in newborn infants. J Pediatr1970; 76: 848-52. 